\title{
Ethical aspects of donor consent in transplantation
}

\author{
John Mahoney Heythrop College (University of London), London
}

Two recent events have caused renewed anxiety concerning the ethics of donor transplantation. The first is the report of the British Transplantation Society and the second is the Bill introduced by Mr Tam Dalyell MP (see page 6r of this issue) in which he seeks to establish by law that unless an individual in his life time has expressly contracted out his organs may after death be used for transplantation. Dr Mahoney in this paper therefore examines from the point of view of ethics some of the personal and social aspects of both proposals.

The ethical issues involved in transplantation have been brought into sharper relief recently as a result of the report ${ }^{1}$ of the British Transplantation Society and of the attempt by Mr. Tam Dalyell to change existing legislation in favour of 'contracting out' and of defining death in terms of 'brain death'. The purpose of this essay is to explore some of the ethical issues involved in transplantation and particularly those connected with donor consent.

The technique of successful transplant operations is a comparatively recent development in medicine and it has inevitably given rise, for the individual as for society, to a whole range of ethical questions. Some, of course, are similar in character to the ethical implications of all developing techniques and their application, such as the weighing of risks involved in early experimentation, the likelihood and degree of success in particular cases, the danger of premature generalization, the need for informed and free consent on the part of those involved, and the justification of investment in terms of resources and personnel. Others, however, are peculiar to the very concept of transplantation, insofar as this relates not simply to the implantation of organs but to their transference from another individual, and notably to their prior extraction from another human body. It is here, of course, that for the transplant surgeon further questions arise in connexion with the compatibility and viability of donor organs, but these are subordinate to much wider considerations concerning the person of the donor himself. And these wider considerations vary

1British Transplantation Society (1975). The shortage of organs for clinical transplantation: Document for discussion. British Medical fournal, I, 25I-255. according as the transplantation is undertaken from a living donor or from a dead donor.

\section{The moral obligations for live donors}

Organ donation by a living donor is widely regarded as a humane and generous, even heroic, contribution to a fellow human being whose quality of life is severely impaired. And for the Christian it is further seen to be a practical instance of the self-sacrificing and loving concern for one's neighbour which was inculcated and exemplified by Jesus. The position has been put forward and held within the Roman Catholic Church that the donation to another during one's life time of an irreplacable bodily organ involves a self-mutilation which offends against the 'principle of totality', that is, the principle that a part of the living human organism may be removed only in the interests of the whole body or, according to a refinement, of the whole individual. At its best, and in its original intent, such a principle only enshrines the commonsense attitude that no one will undergo an operation unnecessarily, while in its extension it has been used against arguments for sterilization, whether compulsory or voluntary. And at its worst it is seen as a self-regarding rule for action which has been found simply unconvincing in the face of a steady human and Christian persuasion that donation of an inessential organ to one less fortunate is legitimate and laudable. The lesson for other areas of behaviour may be salutary. But, of course, the individual contemplating consent to a potentially hazardous course of action will be morally obliged to take thought as to how it will influence his own future, and whether, and to what extent, it will conflict with the claims which others, such as relatives or dependants, may legitimately have upon him. And in this connexion he has a moral right to all the relevant available information concerning the outcome, both for the recipient and for himself, as well as a duty to weigh the foreseeable results of his action for all concerned. Indeed, it might be argued that consent to such donation should be a shared decision of the donor and those closely related to him.

Interpersonal element in donor transplantation

It might reasonably be thought that the ethical 
implications of consent for a living donor are simple compared with those currently debated in connexion with postmortem transplantation. But one further point may be usefully considered before passing to the latter. The situation of transplant from a live donor, and the element of selfgiving to another which it involves, highlight the interpersonal element which is arguably present in every voluntary transplantation but which may easily be ignored by regarding even cadaveric transplantation as a routine quarrying for replacements or as impersonal 'spare-part' surgery. Contemplation of the distressing statistics relating, for instance, to the current shortage of kidneys for transplant could give rise to the impression that individuals in their life time or close relatives who are unwilling to make cadaver organs available are in some vague way offending against society or morally responsible for this 'social problem'. But statistics can be depersonalizing as well as impersonal. And the real point at issue even in cadaveric transplantation is the extent to which one individual may, or should, be willing for his body to be used to help another individual, or possibly two. Admittedly this basic question is multiplied today a thousandfold, but the sheer number of individual cases does not, or at least should not be allowed to, obscure the fact that what is in question is whether or not one human being can be of help, not to thousands of his fellows, far less to 'society', but to one other human being in need. The multiplicity of cases of, for instance, renal failure does constitute a social problem, and to that extent society may rightly wish to take legal steps to alleviate it. But it would be regrettable if society in legislating impersonally to solve the social implications of a multitude of individual problems were in the process to destroy the interpersonal character of transplantation and the aspect of humane and voluntary service of another which is intrinsic to it.

\section{Postmortem transplantation}

This is one reason why, turning now explicitly to postmorten transplantation, society should think very seriously indeed before resorting to contractingout legislation as a solution to the problem of supply and demand. For to see it in these terms alone, or even primarily in these terms, is to select only certain human tragedies for sympathetic consideration and in the process to add an element of social pressure to others. Of course, Mr Dalyell's Bill, which, unlike the Transplantation Society's report, advocates this radical change in legislation, contains provision for the individual to register his objection against his organs being extracted after death and used in transplantation. But the onus is thus placed on the dissenting individual in a way which might be justifiably regarded as an imposition and an intrusion upon his privacy and liberty. The elderly and infirm may not be reassured that such universal legislation will not in point of fact apply to them, and the uneducated may have difficulty coping with registering an objection. Fear of death casts a long shadow before it for many people an this will scarcely be lightened for them by othef fears, however unreasonable, being added. And, of course, in a contracting-out situation any mistake omission in the records or error in consulting the will tend to act against the stated intention of those who are under the impression that their expressed wishes will be respected. And even those who det not register an objection may be consenting by silence out of fear of being considered antisocigy rather than out of personal conviction.

Moreover, a contracting-out situation pays no respects to the bereaved nor to their wishes. It is indeed reasonable to expect, or even to require, that relatives will respect and comply with the explicitly stated intentions of a deceased persom even should they prefer otherwise. But it is less than humane, and may be compounding a family tragedy, in the absence of any such statement to ignore either the relatives' understanding of how the deceased would have wished his remains to be treated or their own wishes in the matter. Intrusion at such a time to seek approval for an organ to be removed is no doubt an unpleasant task for the surgeon, but it may well be an even more emotionaly distressing experience for a bereaved parent of spouse to be informed, or to learn, that organs would be, or had been, removed without family wishes of interests being consulted. At a time of tragic loss it may very well be that some will be consoled know that tragedy can be turned to life-giving effect for another individual or another family. But this cannot lightly be presumed in an emotion-filled and shock-filled situation; and it certainly does not appear fit matter for Parliamentary enactment to intrude on grief at such a time.

\section{Contracting-out legislation - an inhuman solution}

It is such considerations as these which lead one to conclude that a simply bureaucratic decision to introduce a contracting-out situation, however weff intentioned towards some unfortunate members of society, is an inhuman solution to a complex series of human problems. Consent in such an arrange ment savours more of conscription than of voluntary service, and to that extent should be considered only as a last resort in a potentially disastrous socia situation. It is much more reasonable, human and humane, though of course less efficient, to rely upoi public education and fully informed and frees consent. Nor, in considering this aspect of the problem, should the sensitivities of the potentig recipient be ignored in what is, as has been pointed out, basically an interpersonal donation. Whife 
gratitude for another's generosity may give, as some have observed, a fresh purpose as well as a new lease to life, the situation of being the recipient of another's bodily organ because he neglected or felt ashamed or did not know how to register an objection, or against the express wishes of his family might in similar fashion result in feelings of guilt or remorse which would do little to enhance the true quality of life.

\section{Definitions of death}

Possibly, however, the major factor to be considered in the ethics of transplantation of organs after death is that of how death itself is to be defined and whether, as advocated by the Transplantation Society's report and by Mr Dalyell, brain death should be accepted as sufficient indication that life is extinct. It is, after all, not unnatural that individuals whose consent is sought or intended to be presumed for removal of organs after death should be vitally concerned about what criteria shall be used to pronounce them dead. And apprehension about the establishment of such criteria, and about the motivation for pressing for their acceptance, will do little to encourage consent, or indeed support, for transplantation.

\section{THE CONCEPT OF BRAIN DEATH}

In its first recommendation, at best unhappily and at worst ominously phrased, the Transplantation Society 'agreed that there was a need to accept that a person was dead when it was established that he had suffered an irreversible cessation of brain function and was incapable of spontaneous respiration. It is true, of course, that the concept of brain death has been evolved in situations other than those concerned with transplant donors and that it has become a humane and helpful indication when decisions are required about whether or not to resuscitate or prolong intensive care procedures. In such cases, however, the presumption of the public at least is not that the patient has died but that the patient should now be allowed to die. But with the development of transplant surgery, and perhaps especially of heart transplants, a new application of the definition of brain death has opened up and a new factor, that of urgency, has been injected into the situation. Indeed, it is one of the merits of the report of the British Transplantation Society that it brings out so clearly how critical is the acceptance of brain death as sufficient justification for the timely removal of transplant organs. And the incentive is strong to foreshorten one's view of what constitutes death when such a foreshortening can also lead to benefiting the life of another person. But precisely for that reason the utmost scrutiny must be exercised by all concerned, that is, everyone, to ensure that some of the more obvious beneficial results of a new definition of death do not dominate one's thinking about that definition, nor even influence one's thinking about when death actually takes place. The medical profession itself has introduced the safeguard in transplant operations that doctors who certify the death of a potential donor should not be members of the transplant team. And if such careful separation is acknowledged as necessary and desirable in applying the criteria for death in a particular case, it is all the more reasonable as well as necessary that consideration of transplant benefits should be entirely divorced from deciding what the criteria for death shall be.

\section{NEW ATTITUDES TO BRAIN DEATH}

Until comparatively recent times it was universally accepted that cessation of spontaneous breathing and spontaneous heart beat over a period of time indicated that life was extinct. Progress in medicine has made it possible on occasions to reverse this cessation, and further progress has made it possible also to determine the cessation of spontaneous cerebral function as a significant factor in identifying the onset of death. But whereas one might reasonably expect that cessation of brain activity would now be welcomed as an additional safeguard alongside heart death and lung death to reach certainty that a person has died, on the contrary brain death is proposed as an alternative criterion for pronouncing death even although the heart may continue for some time to beat spontaneously. It was this change of approach, undoubtedly strengthened by the need in various countries for viable donor organs, which prompted the writer to ask in The Times (3 February 1975) whether one would countenance the burial of someone whose heart is still beating. It is not a captious question, nor an emotional one. But it is intended to be a shocking one, aimed at probing how far the shift from viewing brain death as sufficient indication to discontinue treatment to that of accepting it as sufficient criterion for pronouncing already dead has been influenced by such essentially extraneous considerations as the benefits accruing to others. In dying no less than in transplanting time is a crucial factor, and the fundamental ethical dilemma is whether it is justifiable to incur the risk of taking the last vestiges of life from one person in an attempt to improve the life of another. It may well be that the last right we have to recognize in the dying person is not after all the right to be allowed to die when hope has gone, but beyond that the right - and the time - to prove that he has in fact died! And until some universally accepted concept of death is achieved the possibility, and perhaps even the propriety, of an increase in consenting donors will remain doubtful.

\section{The common understanding of death}

The major ethical aspects of donor consent in 
transplantation appear, then, to be concerned with the possibility of legislation presuming consent and with a revolutionary change in the common understanding of death. Both have enormous social as well as intimately personal implications well beyond the range of medical practice. And in the circumstances one can welcome not only t Transplantation Society's invitation of publif discussion of its report but also the decision of the Minister of State for Health, as a result of Ner Dalyell's Bill, to commission an enquiry into pub opinion on the subject. 